\title{
A (IN)EXISTÊNCIA DA TERCEIRIZAÇÃO NA PERSPECTIVA DA ECONOMIA COLABORATIVA: (DES)CONSTRUÇÃO DO CONCEITO DE ATIVIDADE-FIM E A NEGAÇÃO DA RELAÇÃO DE TRABALHO SUBORDINADO
}

THE (IN)EXISTENCE OF THE OUTSOURCING IN THE PERSPECTIVE OF THE COLLABORATIVE ECONOMY: (DES)CONSTRUCTION OF THE CONCEPT OF END-ACTIVITY AND THE REFUSAL OF THE WORK RELATION-

\section{Lílian de Brito SANTOS 1}

Maria Valquíria Barbosa SANTANA ${ }^{2}$

ISSUE DOI: $10.21207 / 1983.4225 .503$

\section{RESUMO}

\footnotetext{
${ }^{1}$ Professora Assistente do Departamento de Ciências Jurídicas da Universidade Estadual de Santa Cruz (UESC), Ilhéus/BA. Mestra em Master In English Teaching With Emphasis On Tesol pela New Mexico State University. Currículo Lattes: http://lattes.cnpq.br/4320380040933650.

${ }^{2}$ Graduanda em Direito pela Universidade Estadual de Santa Cruz (UESC), Ilhéus/BA. Currículo Lattes: http://lattes.cnpq.br/4833891718270278.
} 
Este artigo visa propor uma reflexão acerca da (des)construção do conceito de atividade-fim num possível modelo de terceirização da economia colaborativa e suas implicações para o Direito Trabalho. A economia colaborativa emerge como uma nova modalidade econômica que vem conquistando espaço no mundo todo e que acarreta mudanças significativas na forma de organização do trabalho. A terceirização proposta pela economia colaborativa ou compartilhada impõe uma (des)construção do conceito de atividade-fim ao desconsiderar a existência da relação de emprego subordinada e ao fomentar práticas de trabalho autônomas e empreendedoras. Essa (des)construção do conceito de atividade-fim e a negação da relação de trabalho subordinada afasta a possibilidade de aplicação das normas trabalhistas nessa nova modalidade de relação de trabalho.

Palavras-chave: Atividade-fim; Economia Colaborativa; Terceirização.

\section{INTRODUÇÃO}

A terceirização das relações de trabalho não é um fenômeno novo, mas até hoje suscita alguns questionamentos e fomenta inúmeros debates, principalmente por se tratar de um fenômeno que apresenta muitas faces.

Neste estudo, procura-se analisar a terceirização dentro da perspectiva da economia colaborativa, uma nova modalidade econômica que vem despontando nos últimos anos como uma alternativa à crise do capitalismo industrial e que propõe mudanças significativas na forma de organização do trabalho, cujos reflexos incidem nos conceitos de relação de trabalho subordinado (relação de emprego) e atividade-fim.

Nesse sentido, nos propomos a investigar quais as implicações que um possível modelo de terceirização dentro da economia colaborativa traz para a (des)construção dos conceitos de relação de trabalho subordinado e atividade-fim, bem como seus reflexos no Direito do Trabalho. E para alcançarmos esse propósito, buscamos na literatura nacional e estrangeira, bem como nos meios de informação eletrônicos, subsídios para comporem esse trabalho.

O presente estudo encontra-se organizado em nove tópicos. Nos dois primeiros (tópico 2 e 3), trazemos uma abordagem acerca da origem e evolução histórica da terceirização, bem como sobre seus conceitos e sentidos.

No tópico 4, fazemos uma breve conceituação da relação de emprego e da atividade-fim. O tópico 5 traz uma exposição sobre as formas 
de organização da produção e do trabalho no contexto da economia capitalista industrial. O próximo tópico (6) visa explicar a economia colaborativa e sua perspectiva em torno da produção, do consumo e das relações laborais.

Em seguida, no tópico 7, tratamos da negação da relação de emprego e da (des)construção do conceito de atividade-fim no modelo de relação de trabalho proposto pela economia colaborativa. O tópico 8 está reservado para uma breve discussão relativa às implicações da (in)existência de um modelo de terceirização proposto pela economia colaborativa. O tópico de número 9 evidencia as implicações que a negação da relação de emprego e a (des)construção do conceito de atividade-fim trazem para o Direito do Trabalho.

Tenciona-se que esse estudo possa trazer reflexões e contribuições significativas para a academia e para a sociedade de modo geral acerca da temática estudada.

\section{TERCEIRIZAÇÃO: ORIGEM E EVOLUÇÃO HISTÓRICA}

A terceirização tem sua origem na expressão setzen-out-system palavra utilizada para designar a forma pela qual tecelões e filandeiros trabalhavam em suas residências utilizando-se de suas ferramentas e recebendo dos comerciantes para quem prestavam serviços apenas a matériaprima e a remuneração. Esse modelo de produção era chamado de façonismo (SOBRINHO, 2008, p.78).

Com a Primeira Revolução Industrial (séculos XVIII-XIX), a produção manufaturada demandava uma mão-de-obra capaz de atender ao mercado cada vez mais crescente. Era necessário, então, um espaço reservado para produzir. A necessidade de reunir os trabalhadores em um espaço físico para controlar melhor a produção fez surgir as primeiras fábricas. (VIANA, 2015, p.24)

Embora de forma muito precária, essa revolução incluiu ao processo de confecção de manufaturas alguns avanços tecnológicos. Na indústria têxtil, a inserção da cisalhadeira, máquina que servia para cortar e aparar tecidos, deixou muitos trabalhadores que exerciam a função de corte de tecidos, temerosos em relação à possibilidade de perderem seus empregos, o que os levou a destruírem as máquinas. Esse movimento ficou conhecido como ludismo. $\mathrm{O}$ parlamento inglês puniu esses trabalhadores com a pena 
de morte. Daí em diante, muitos trabalhadores ingleses passaram a protestar contra a inserção de máquinas na indústria.

Conforme Sobrinho (2008, p. 79),

No contexto do conflito entre o homem e a máquina, o trabalhismo inglês revela as origens da terceirização sob a égide capitalista. Thompsom (1987, p.90 e 101) diz que no final do século XVIII alguns comerciantes compravam tecidos e encomendavam os acabamentos às oficinas situadas em Leeds ou nas aldeias de West Riding. Os negociantes repassavam trabalhos para oficinas situadas em condados distantes, deslocando assim a produção até então situada nos grandes centros urbanos, nos quais existia a pressão dos 'ludistas'."

Defluímos do exposto, que a terceirização tem estreita relação com as transformações pelas quais o sistema o capitalista passou no decorrer dos anos, bem como com os avanços tecnológicos e, principalmente, com a necessidade de se reduzirem os custos da produção.

Vale ressaltar, que a ideia de reunir para produzir perdurou durante a Segunda Revolução Industrial (1850 e 1945), período em que se acentuou a verticalização do processo produtivo com o aparecimento dos modelos de produção de Taylor e Ford.

Com a crise da superprodução dos anos de 1970, tornou-se imprescindível repensar a organização produtiva e as formas de trabalho. Acumulação flexível e sua proposta de flexibilização da produção e do trabalho favoreceram o surgimento do modelo toyotista de produção nos Estados Unidos, modelo que foi aperfeiçoado pelo engenheiro da Toyota Taichi Ohnio

De acordo Alves (2008, p. 101),

A produção difusa é o que o toyotismo irá salientar por meio da constituição das redes de colaboradores, ampliando a terceirização e as redes de subcontratação. O espírito do toyotismo impulsiona o aumento da utilização da terceirização e do trabalho por encomenda, ou ainda, das formas marginais de trabalho: trabalho em domicílio, trabalho clandestino. Enfim, a 
'externalização' de uma parte do pessoal realiza-se por meio do apelo à mão-de-obra temporária.

Nesse sentido, percebemos que a terceirização se difunde com o toyotismo, que com sua ênfase na descentralização das etapas produtivas cedeu espaço para que outras empresas pudessem participar da produção. Como afirmam Menezes e Mendes (2014, p. 62), "[...] o sistema 'fordista' não admitia qualquer espécie de terceirização, pois se entendia que o controle econômico sobre todas as etapas de produção representaria maior eficiência, produtividade por homem e, consequentemente, lucro [...]." A restruturação produtiva promovida pela empresa Toyota ao delegar uma ou várias etapas da produção para terceiros, a fim de reduzir os custos e aumentar a produtividade, fez surgir o fenômeno da terceirização.

Nesse contexto, a fábrica passou a se organizar de forma mais flexível. O processo de globalização permitiu a transnacionalização da economia, a produção passa a ocorrer em escala global, tornam-se cada vez mais comuns empresas que produzem partes isoladas de um produto em países diferentes, com o propósito de reduzir os custos de produção. Nas palavras de Hobsbawm (1995, p. 275),

[...] A linha de produção cruzava agora não hangares gigantescos num único local, mas o globo. Algumas delas paravam nas extraterritorialidades 'zonas francas' ou fábricas offshore, que agora começavam a espalhar-se, esmagadoramente pelos países pobres com mão-de-obra barata, e sobretudo feminina e jovem, outro novo artifício para escapar ao controle do Estado $[\ldots]$

Dessa forma, a partir do momento em que a fábrica deslocou-se para fora de seu lugar de origem, surgem novos modelos de terceirização, conhecidos como outsourcing e offshoring.

Segundo Basso (2008, p. 92), outsourcing e offshoring são gêneros da terceirização. Para esse autor,

a) o chamado outsourcing - que dá a ideia de uma "fonte externa" - é a terceirização de serviços ou a produção de componentes repassada a outra empresa para executá-los dentro ou fora dos muros da tomadora, mas dentro do território nacional; normalmente, 
por questão de logística, em prédio contíguo ou próximo da contratante, exceção feita aos serviços de informática que independem de distância. Exemplos típicos são os casos Fiat em Betim/MG, e da GM no ABC Paulista, em que os parceiros diretos estão localizados dentro da planta; b) o segundo grande gênero é o denominado offshoring, ou seja, aquela terceirização feita "fora da praia" do tomador dos serviços, normalmente no exterior. São expressivos os números, hoje em dia, desse tipo de terceirização, tendo como destinos a Índia e a China, principalmente nas áreas de informática e metalurgia, respectivamente.

Desse trecho, concluímos que enquanto no modelo outsouring a terceirização ocorre através do repasse da produção ou do serviço de uma empresa para outra no âmbito local, no modelo offshoring a transferência da produção ou do serviço é realizada por outra empresa no exterior, a filial. No caso da terceirização offshoring, o que motiva a realização do trabalho fora do país não é apenas a dificuldade de realizá-lo de forma eficaz no âmbito local, como também a redução dos custos, uma vez que o salário em outros países, principalmente nos países em desenvolvimento, é menor.

Destarte, a terceirização é um fenômeno em constante processo de transformação. Ela evolui e se adapta às necessidades do sistema capitalista ao mesmo tempo em que esse sistema precisa dela para continuar operante.

\section{TERCEIRIZAÇÃO: CONCEITOS E SENTIDOS}

Como afirma Martins (2014, p. 6), o vocábulo terceirização deriva do latim tertius, que em sentido geral, indica a existência de um terceiro numa relação entre duas pessoas. No que se refere às relações de trabalho, o terceiro pode ser um obreiro contratado para realizar uma atividade dentro da empresa ou uma empresa contratada para executar uma etapa da produção. Maurício Godinho Delgado expõe que a terceirização

É o fenômeno pelo qual se dissocia a relação econômica de trabalho da relação justrabalhista que lhe seria correspondente. Por tal fenômeno insere-se o trabalhador no processo produtivo do tomador de 
serviços sem que se estendam a este os laços justrabalhistas, que se preservam fixados com uma entidade interveniente. (DELGADO, 2015, p.407)

Nessa perspectiva, Delgado (2015) entende que o fenômeno da terceirização permite o surgimento de uma relação trilateral entre uma empresa que contrata serviços, outra que fornece os serviços e um obreiro que executa os serviços contratados, sem que haja nenhum vínculo empregatício entre esse e a empresa tomadora do serviço.

Mendes e Meneses (2014, p. 34) por sua vez, entendem que a terceirização "[...] Trata-se de um impulso interno das organizações capitalistas privadas ou estatais, de externalizar suas atividades. Esse movimento baseado em inovação de gestões assume várias formas jurídicas [...]". Isso significa que a terceirização assume contornos diferentes em cada país e que, consequentemente, o tratamento legislativo dado a esse fenômeno também é diferente.

Na ótica de Giosa (1994, p. 11), a terceirização pode ser entendida como uma moderna técnica de administração de empresa que implica em mudanças em toda a dinâmica organizacional da mesma com a finalidade de aferir resultados positivos em torno da atividade-fim.

Cavalcante Júnior (1996, p. 73) entende que a terceirização, por permitir maior especialização e produtividade à empresa, não pode estar restrita somente às atividades acessórias devendo ser desenvolvida na forma de parceria entre as empresas.

Martins (2014, p. 10) esclarece que a terceirização não encontra definição na legislação e que ainda não existem normas jurídicas disciplinando essa matéria. Para esse autor, a terceirização é uma forma de organização de empresas que visa interligar a atividade-meio à atividade-fim de uma empresa. Souto Maior também corrobora desse entendimento ao afirmar que:

A terceirização é, assim, apresentada como técnica moderna de produção, fruto da reengenharia administrativa das empresas, inseridas num contexto de concorrência global, que lhes exige uma postura de encurtamento de custos e eficiência produtiva. A partir desses postulados, explica-se que uma empresa, para ser eficiente e global, deve preocupar-se com suas finalidades próprias, deixando, para 'parceiras', outras que sejam periféricas ou menos importantes. E, assim, 
justifica-se, juridicamente, que uma empresa contrate (denominada, então, tomadora de serviços) outra para lhe prestar serviços (a prestadora de serviços), mesmo no interior do estabelecimento da primeira, em se tratando de serviços desvinculados da atividade primordial desta.( MAIOR, 2011, p. 650)

Para esse jurista, a terceirização não só é um fenômeno criado pelas empresas na tentativa de se tornarem mais eficientes e produtivas como também é uma construção da jurisprudência que visa normatizar e resolver os conflitos que o vínculo estabelecido na relação triangular traz às relações trabalhistas.

De acordo com o professor Márcio Túlio Viana, o vocábulo terceirização indica a existência da interferência de um terceiro na cadeia produtiva. Esse terceiro pode ser o sindicato, o legislador, o fiscal do trabalho e até mesmo o empregador (VIANA, 2015).

Para o mestre Viana (2015, p. 16), a terceirização pode ser classificada como terceirização interna e terceirização externa. Segundo ele, "[...] Na primeira, a empresa traz trabalhadores alheios para dentro de si, na segunda, joga para fora de si não só os trabalhadores seus, como etapas de seu ciclo produtivo." Ou seja, enquanto na terceirização interna um terceiro trabalhador se insere na cadeia produtiva, na terceirização externa uma ou várias etapas da produção são delegadas a outra empresa.

Essas modalidades de terceirização apresentam componentes e efeitos diferentes. De acordo com Viana (2015, p. 20),

A terceirização externa lembra o trabalho por conta própria. Uma empresa contrata a outra, mas o que lhe interessa é o produto final. Por isso, só ao termino da produção passa a ter a propriedade sobre ele.

A terceirização interna se articula com o trabalho por conta alheia. A empresa tomadora vai se apropriando do trabalho dos terceirizados á proporção em que eles executam. Aproveitam a força de trabalho do mesmo modo que faria se os tivesse contratado como empregados seus.

Dessa forma, enquanto na terceirização interna o trabalho do obreiro é desenvolvido dentro da empresa tomadora do serviço como se 
esse obreiro fosse empregado vinculado a essa empresa, na terceirização externa outra empresa é contratada para executar uma ou várias etapas da produção, cujo produto final pertence à empresa tomadora.

É importante salientar que, a compreensão do fenômeno da terceirização perpassa pela questão das responsabilidades justrabalhistas, uma vez que na relação trilateral - empresa tomadora, empresa prestadora de serviços e obreiro, essa questão é dirimida. Esse último executa o serviço em favor da empresa tomadora de serviço, mas com essa não tem nenhum vinculo empregatício. $\mathrm{O}$ vínculo do obreiro está diretamente ligado à empresa prestadora de serviços.

Todavia, a jurisprudência brasileira ao disciplinar a relação terceirizada, na Súmula 331 TST, embora seja omissa em relação ao vinculo entre o obreiro e a empresa tomadora, prevê a responsabilidade subsidiária dessa, quando houver o inadimplemento de obrigações. (DELGADO, 2015).

Como bem salienta o mestre Viana (2015, p. 55), “[...] a terceirização oferece à empresa uma rota de fuga, não só confundindo responsabilidades como tornando menos visível a exploração de mão-de-obra". E o cerne do fenômeno da terceirização são justamente as responsabilidades trabalhistas e a exploração da mão de-obra.

\section{RELAÇÃO DE EMPREGO E ATIVIDADE-FIM: CONCEITOS E CARACTERÍSTICAS}

No âmbito do Direito do Trabalho, enquanto a definição do conceito de relação do trabalho é fundamental para a compreensão da incidência das normas justrabalhistas, o entendimento acerca do conceito de atividade-fim é essencial a compreensão do fenômeno da terceirização. Como explica Júnior (2013, p. 150) “[...] toda relação de emprego (espécie) é uma relação de trabalho (gênero). Mas nem toda relação de trabalho (gênero) é uma relação de emprego (espécie)." Isso significa dizer que a relação de trabalho (relação lato sensu) pode ser compreendida como uma atividade realizada por um sujeito em favor de outro, que pode conferir ou não ao primeiro uma contraprestação financeira e não implica a existência de subordinação entre eles. Já a relação de emprego (relação strictu sensu), pressupõe a existência de uma relação de trabalho, uma vez que nela também se desenvolve uma atividade em prol de alguém, mas ao contrário do que 
acontece na relação lato sensu, na relação empregatícia é indispensável a subordinação e a contraprestação financeira entre os sujeitos. Isso por que, para o professor Júnior, a relação de emprego tem componentes específicos como onerosidade, pessoalidade, subordinação e não-eventualidade que a diferenciam da relação de trabalho (JÚNIOR, 2013, p. 145)

Ao distinguir as relações de trabalho, Torres $(2008,265)$ corroborando do mesmo pensamento de Júnior (2013), define as relações de trabalho strictu sensu como "[...] aquelas em que se identifica presença dos elementos caracterizadores da relação de emprego." Ao passo que as relações de trabalho lato sensu "[...] são aquelas que, embora tenham por objeto o trabalho humano, carecem de alguns dos elementos ínsitos à relação de emprego" (TORRES, 2008, p. 266). Sendo assim, o que caracteriza a relação empregatícia são os requisitos da pessoalidade, subordinação, a prática de atividades não-eventuais e de caráter oneroso. São esses elementos que, consequentemente, determinam a existência ou não da relação de emprego entre o obreiro e a empresa.

Esses requisitos citados acima, são elementos constitutivos tanto da atividade-meio quanto da atividade-fim de uma empresa.

De acordo com Delgado (2015 p. 489),

Atividades-fim podem ser conceituadas como funções e tarefas empresariais e laborais que se ajustam ao núcleo da dinâmica empresarial do tomador dos serviços, compondo a essência, dessa dinâmica e contribuindo inclusive para a definição de seu posicionamento e classificação no contexto empresarial e econômico. São, portanto, atividades nucleares e definitórias da essência da dinâmica empresarial do tomador de serviços $[\ldots]$

Nessa perspectiva, verificamos que a dinâmica de organização do serviço ou da produção pressupõe a existência de uma relação direta entre empregador e empregado que se sustenta no paradigma de trabalho subordinado consagrado nos artigos $2^{\circ}$ e $3^{\circ}$ do Título I da Consolidação das do Trabalho ${ }^{3}$.

\footnotetext{
${ }^{3}$ Art. $2^{\circ}$ - Considera-se empregador a empresa, individual ou coletiva, que, assumindo os riscos da atividade econômica, admite, assalaria e dirige a prestação pessoal de serviço. $\S$ $1^{\circ}$ - Equiparam-se ao empregador, para os efeitos exclusivos da relação de emprego, os profissionais liberais, as instituições de beneficência, as associações recreativas ou outras
} 
A atividade-fim tem seu conceito estabelecido no Direito Empresarial, mas é no Direito Civil, mais precisamente no que refere ao Direito das Obrigações e suas definições acerca das obrigações de resultado e obrigações de meio que a palavra atividade-fim tem seu conceito estruturado (PEREIRA; SOUZA, 2014, p.187).

A necessidade de conceituar e caracterizar a atividade-fim é indispensável, principalmente quando no campo da terceirização, pois é tomando como pressuposto a atividade-fim que se pode determinar os limites desse fenômeno, tipificar sua ilicitude e lesões aos direitos trabalhistas. Isso por que a jurisprudência brasileira prevê a possibilidade de terceirização da atividade-meio. Apesar da atividade-meio ${ }^{4}$ não ser o foco desse estudo, vale salientar que ainda persiste na doutrina uma dificuldade prática de distinção desses dois institutos.

Sobre isso Pereira e Souza esclarecem que:

É importante ressaltar que o critério definidor das atividades não pode ser absoluto, pois, conforme a evolução social e trabalhista, atividades antes tidas como 'fins' podem vir a se tornar atividades-meio. Dessa forma, esses conceitos não podem ser solidificados ou delimitados a um número fechado de atividades. (PEREIRA; SOUZA, 2014, p.187).

Acerca dessa assertiva é importante salientar que as mudanças na organização da esfera produtiva podem modificar a essência das atividades fim e meio, de modo que uma empresa pode fazer de sua atividade-meio a atividade principal ou vice-versa.

instituições sem fins lucrativos, que admitirem trabalhadores como empregados. $\S 2^{\circ}$ - Sempre que uma ou mais empresas, tendo, embora, cada uma delas, personalidade jurídica própria, estiverem sob a direção, controle ou administração de outra, constituindo grupo industrial, comercial ou de qualquer outra atividade econômica, serão, para os efeitos da relação de emprego, solidariamente responsáveis a empresa principal e cada uma das subordinadas. Art. $3^{\circ}$ - Considera-se empregado toda pessoa física que prestar serviços de natureza não eventual a empregador, sob a dependência deste e mediante salário. (SARAIVA, 2012).

${ }^{4}$ Assim como na atividade-fim, na atividade-meio também existe uma relação de emprego não-eventual, subordina, pessoal e onerosa, porem a finalidade dessa atividade não é a atividade principal da empresa. Ela é somente uma atividade acessória que possibilita a realização da atividade principal. E a subordinação do obreiro está atrelada a empresa prestadora do serviço e não a empresa tomadora. 


\section{AS FORMAS DE ORGANIZAÇÃO DO TRABALHO NO PARADIGMA TRADICIONAL}

No sistema capitalista de produção, a função do trabalho sempre foi impulsionar o consumo. É através dele que as indústrias fomentam e renovam seu ciclo produtivo, aumentando e diversificando a produção de mercadorias, gerando empregos, expandindo seus mercados para se tornarem cada vez mais competitivas e se afirmarem no mercado. Por essa razão, o sistema capitalista está em constante busca pelo equilíbrio entre produção e consumo. Entretanto, como produção e consumo nem sempre caminham no mesmo ritmo, o sistema de produção capitalista enfrenta constantemente os ciclos de crise.

Contornar as crises no sistema de produção capitalista requer a adoção de uma série de medidas, entre elas a organização do processo produtivo e, consequentemente, das formas de organização do trabalho.

Uma das formas de organização do trabalho que mais se destacaram dentro do sistema capitalista foi idealizada pelo empresário norte-americano Henry Ford na segunda década do século XX. Ford, visando aumentar a produção de carros em sua fábrica e, consequentemente, a venda desses veículos, elaborou um modelo produtivo que se baseava na produção em grande escala por meio da inserção de uma esteira de produção e com o uso de tarefas repetitivas.

Conforme Batista (2008, p. 39),

[...] A indústria automobilística fordista sistematizou o trabalho mecanizado via esteira de montagem. Com a padronização de poucos modelos, no inicio o carro modelo $\mathrm{T}$ de cor preta, Ford customizou a produção de carros em serie, e que após a Segunda Guerra, ao lado dos métodos desenvolvidos por F. Taylor, pode abastecer o consumo de massa.

Nesse sentido, esse modelo de produção e organização do trabalho por ser realizado de forma mecanizada e por meio de tarefas repetitivas, precisava tão somente de mão-de-obra com pouca ou nenhuma qualificação, que se desenvolvesse sob o comando atento de um técnico que coordenava a atividade produtiva. Contudo, a universalização do modelo de produção fordista só foi possível com a incorporação das técnicas de 
administração financeira desenvolvidas por F. W. Taylor na primeira metade do século XX.

Taylor idealizou um modelo de administração científica de empresa cujo objetivo e princípio basilar é “[...] assegurar o máximo de prosperidade ao patrão e, ao mesmo tempo, o máximo de prosperidade ao empregado." Para isso, defendeu como fundamentos desse novo modelo de administração o binômio: altos salários e baixo custo de produção (TAYLOR, 1990, p. 25). A administração científica de Taylor pautava-se na racionalização do trabalho, cujo modelo versava na separação entre quem prepara (planeja) a atividade laboral e quem a executa. Sobre isso discorre esse autor:

[...] A fim de que o trabalho possa ser feito de acordo com as leis cientificas, é necessário melhor divisão de responsabilidades entre a direção e o trabalhador do que atualmente observada em qualquer dos tipos comuns de administração. Aqueles na administração, cujo dever é incrementar essa ciência, devem também orientar e auxiliar o operário sob sua chefia e chamar a si maior soma de responsabilidades do que, sob condições comuns, são atribuídas a direção (TAYLOR, 1990, p.34)

Deflui-se do trecho transcrito, que o modelo de organização do trabalho desenvolvido por Taylor tinha como propósito alcançar a eficiência através do máximo de rendimento da produção. E para isso, Taylor propõe que ocorra a seleção do trabalhador conforme suas aptidões e, posteriormente, seu treinamento (princípio do preparo do obreiro), o controle do ritmo do trabalho (princípio do controle) e a distribuição das tarefas conforme o grau de responsabilidade dos trabalhadores para assegurar a disciplina na cadeia de produção (princípio da execução). Somente assim, é possível obter a produção em série (TAYLOR, 1990).

Henry Ford, por sua vez, lançou mão da proposta de racionalização do trabalho taylorista e associou a ela a especialização. Ford utilizouse da linha de montagem automotiva para fomentar a produção em massa com alto nível de padronização.

Como afirmam Menezes e Mendes (2014, p. 62):

O fordismo pautava-se na generalização/homogeneização. Necessitava de um contingente imenso de 
trabalhadores, embora não se fundasse no trabalho criativo (nos moldes do trabalho artesão) ou reflexivo (intelectual), mas relegava aos operários funções repetitivas, mecânicas e simples, desprestigiando a especialização técnica e/ou a habilidade individual.

Sendo assim, no modelo fordista/taylorista, a organização da produção era regida pela lógica do máximo de produção em mínimo de tempo e com mínimo de esforço, através do controle do processo de trabalho, que se organizava de forma hierárquica, ou seja, cada trabalhador atuava apenas na função a que fora designado e se submetia às ordens dos técnicos e superiores. No sistema fordista/taylorista, o controle da produção e do trabalho envolvia desde o cultivo da matéria prima até a venda do produto no estabelecimento comercial (Menezes e Mendes, 2014,p. 62).

Essa forma centralizada de organização do trabalho perdurou por muitas décadas não só porque se desenvolveu em um contexto histórico em que o mercado de consumo absorvia de forma satisfatória os produtos e mercadorias, mas pelo fato de que um dos pilares desse modelo de gestão era minimizar a participação dos trabalhadores nos sindicatos e para isso eram pagos altos salários aos operários, o que os induzia a se reconhecerem como um consumidor em potencial. Nesse sentido, Viana (2015, p. 30) afirma que:

A lógica passou a ser a de transformar cada trabalhador em empregado e cada empregado em consumidor - realimentado o ciclo. Com isso, o sistema se tornou menos selvagem, e na mesma medida o sindicato passou a ser cada vez menos revolucionário e mais reformista. Era o chamado pacto fordista.

Assim, com o controle da produção e exercendo influência no poder diretivo dos sindicatos, o modelo fordista/taylorista se difundiu pelo mundo, consagrou-se como um eficiente modelo de organização do trabalho.

Contudo, a partir do momento em que o Estado social-democrata começou a entrar em colapso e a produção capitalista ${ }^{5}$ diminuía seu ritmo,

\footnotetext{
${ }^{5}$ A superprodução capitalista que o próprio modelo fordista ajudou desenvolver, associada as politicas neoliberais e as reivindicações da classe trabalhadora, foi responsável pela grave
} 
emergiu a necessidade de modificar a organização do trabalho. Para adequar o sistema capitalista de produção às políticas do neoliberalismo, que previam a privatização do Estado e a redução dos direitos trabalhistas, era necessário flexibilizar o modo de produção. É assim que surge o modelo de acumulação flexível. Citado por Antunes (2011, p. 28), David Harvey explica que a cumulação flexível é

[...] marcada por um confronto com a rigidez do fordismo. Ela se apoia na flexibilidade dos processos de trabalho, dos mercados de trabalho, dos produtos e padrões de consumo. Caracteriza-se pelo surgimento de setores de produção inteiramente novos, novas maneiras de fornecimento de serviços financeiros, novos mercados e, sobretudo, taxas altamente intensificadas de inovação comercial, tecnológica e organizacional $[\ldots]$

Esse modelo flexível de produção passou a exigir do trabalhador uma atitude bastante diferenciada daquela característica do modo de produção fordista. Era necessário um trabalhador flexível capaz de se adaptar ao trabalho temporário, realizado em âmbito doméstico e sem influência do sindicato (COUTINHO, 2015, p. 70).

Reportando-se, novamente, à teoria de David Harvery, Antunes (2002, p. 25) esclarece que a acumulação flexível tem como algumas de suas características a "' [...] divisão de mercados, desemprego, divisão global do trabalho, capital volátil, fechamento de plantas industriais, reorganização financeira e tecnológica'[...]". Nesse novo modelo de organização da produção, o trabalho repetitivo não era mais compatível com as novas práticas produtivas que exigiam um trabalhador polivalente, capaz de realizar várias etapas da produção. Um trabalhador educado para se adaptar à flexibilidade dos contratos de trabalho, dos salários e tempo de trabalho. E diante dessa necessidade, como salienta Batista (2008, p. 44), o trabalhador passou a atuar como operário-supervisor da máquina, realizando não só a atividade mecânica como também supervisionando sua própria produção.

É nesse cenário que a empresa japonesa Toyota difunde seu modelo de organização produtiva e de gestão do trabalho, que influenciado pela crescente evolução tecnológica e, posteriormente, com o surgimento

crise mundial dos anos de 1970 que fez entrar em declínio a Era de Ouro do capitalismo (HOBSBAWM, 1995). 
da robótica, estabeleceu o paradigma de organização do trabalho sustentado na cooperação. O toyotismo também ficou conhecido como ohnismo porque um de seus idealizadores foi Taiichi Ohno, engenheiro da empresa Toyta que desenvolveu um modelo de organização do trabalho que fazia analogias entre o trabalho realizado na fábrica e os esportes de competição em equipe (ALVES, 2008, p.99).

O ohnismo tem como objetivo a eliminação do desperdício e, consequentemente, a redução dos custos da produção. Para alcançar essa finalidade, Ohno desenvolveu um modelo de produção voltado para a flexibilização do processo de produtivo, associado à diminuição do número de trabalhadores, o que intensificava a jornada de trabalho e exigia um trabalhador polivalente. $\mathrm{O}$ toyotismo tem como pilares a produção just in time, o método kanban e automação (ALVES, 2008, p.106).

Para Ohno, a automação era necessária para tornar as máquinas inteligentes e dar um perfil humano à produção. Conforme Alves (2008, p. 107),

[...] O princípio de automação ou automação com toque humano implica, segundo ele, que "não será necessário um operador enquanto a máquina estiver funcionando normalmente". O que significa que a automação com toque humano contribui para o sistema de multitarefas e de operadores polivalentes[...]

Dessa forma, a proposta de racionalização do trabalho feita por Ohno captura a subjetividade do trabalhador e a agrega ao trabalho em equipe, o que só foi possível devido à inserção da tecnologia na cadeia produtiva.

De acordo com Hobsbawm (1995, p. 394),

[...] Controle de inventário computadorizado, melhores comunicações e transportes mais rápidos reduziram a importância do volátil 'ciclo de estoques' da velha produção em massa, que resultava em enormes estoques 'só para a eventualidade' de serem necessários em épocas de expansão, e depois parava de chofre quando os estoques eram liquidados em épocas de contração. O novo método, iniciado pelos japoneses, e tornado possível pelas tecnologias da década de '70, iria ter estoques muito menores, produzir o suficiente 
para abastecer os vendedores "just in time" (na hora), e de qualquer modo com uma capacidade muito maior de variar a produção de uma hora para outra, a fim de enfrentar as exigências de mudança.[...]

Nessa perspectiva, o modelo de produção definido pelo toyotismo tem por objetivo a produção enxuta e just in time, ou seja, a produção deve ser realizada de acordo com as demandas de mercado, a fim de evitar o desperdício e de contemplar a diversificação que o mercado consumidor exige. No toyotismo, a organização do trabalho está pautada na participação do trabalhador em todas as etapas do processo de produção. Conforme explica Batista (2008, p. 44), “[...] A lógica impôs aos operários um sistema de gestão total que incorporava ao trabalho repetitivo o trabalho multifuncional, intensificando a atividade do trabalho e penetrando na 'alma' do trabalhador." Dessa forma, é possível aproveitar as experiências e conhecimentos dos trabalhadores tornando a empresa mais produtiva e competitiva.

Um dos principais fundamentos do toyotismo é o trabalho realizado em equipe sob o sistema dos Círculos de Controle da Qualidade (CCQ), bem como a descentralização na gestão e realização das tarefas. No toyotismo, as especialidades individuais de cada operário são combinadas ao trabalho em equipe e a excelência da qualidade da produção é decorrente do processo de discussão e solução dos problemas que se realizam nos CCQs (BATISTA, 2008, p45).

Conforme Menezes e Mendes (2014, p. 65), "A organização toyotista, no intento do máximo aproveitamento, reduz não só o estoque de peças, mas também o estoque de mão de obra. O enxugamento passa, igualmente, por outros expedientes de gestão, como a metodologia just in time e o método kanbam 6 .

Mais adiante, Menezes e Mendes (2014, p. 63) enfatizam que o sistema de produção toyotista "[...] rompe, aparentemente, com a verticalização fordista, adotando a estratégia de externalização que corresponde a delegação a terceiros do maior número possível de etapas da produção, especialmente para reduzir custos". E nesse sentido, a opção mais viável para

\footnotetext{
${ }^{6}$ Kanban é uma técnica de gestão japonesa em que a produção é determinada e orientada pela procura do produto no mercado. Através dessa técnica evita-se o desperdício da produção a medida que a produção diversificada é voltada para o consumo rápido e a reposição dos produtos é realizada conforme a demanda. (COUTINHO, 2015, p. 73). Ou seja, o Kanban é o método utilizado para transmitir a ordem de produção.
} 
se obter uma produção enxuta, ou seja, sem desperdício de tempo e recursos materiais, era cedendo uma ou várias etapas da produção a trabalhadores ou empresas especializadas externas à empresa principal.

De acordo com Coutinho, (2015, p. 74) o toyotismo:

“[...] prestigia o trabalho em equipe como pressuposto da multifuncionalidade ou polivalência de cada trabalhador e investe em programas de qualidade total e destina parte considerável deste processo às empresas subcontratadas (terceirizadas), de quem é exigido o acatamento ao padrão aplicado no interior bastante enxuto da empresa principal."

Dessa forma podemos afirmar que é a partir do desenvolvimento do modelo toyotista de produção que o fenômeno da terceirização se difunde nas economias mundiais.

Contudo, assim como aconteceu com o fordismo/taylorismo, o modelo toyotista ${ }^{7}$ também foi abalado pelas crises oriundas do próprio sistema capitalista de produção. Mas dessa vez, a crise do capital fomentou debates em torno da crise climática mundial como um dos elementos desencadeadores da crise econômica que se inicia a partir do ano de 2007 (CHESNAIS, 2009). A questão da limitação dos recursos naturais e da crescente propaganda estimulando o consumismo permitiu o surgimento de um movimento favorável à ideia de consumo consciente, que pretende incentivar as pessoas a consumirem somente o necessário, evitando o desperdício e preservando os recursos naturais.

Essa necessidade de consumo consciente fez surgir a ideia de consumo colaborativo ${ }^{8}$. Segundo Botsman e Rogers (2011, p. 21), “[...] Consumo colaborativo não tem nada a ver com compartilhamento forçado e educado. Pelo contrário, ele coloca em vigor um sistema em que as pessoas dividem recursos sem perder liberdades pessoais apreciadas e sem sacrificar seu estilo de vida [...]". Nessa perspectiva, o consumo é

\footnotetext{
${ }^{7}$ As crises no sistema capitalista não fizeram desaparecer por completo os modelos de produção fordista/taylorista ou toyotista. Esses modelos de gestão ainda são utilizados por algumas

${ }^{8}$ No Brasil, é possível verificar o consumo colaborativo no programa de compartilhamento de bicicletas desenvolvido em algumas capitais do país pelo Banco Itaú. A empresa OLX, um site de classificados gratuitos onde pessoas divulgam produtos que pretendem vender ou trocar também é outro exemplo de consumo colaborativo.
} 
compreendido como uma prática de compartilhamento de bens e serviços cujo objetivo é satisfazer as necessidades de todos através de uma espécie de colaboração.

Paralelo à ideia de consumo colaborativo, emerge o paradigma da economia colaborativa, uma nova modalidade econômica que tem levado algumas corporações ao redor do mundo a repensarem seus modos de produção e organização do trabalho.

\section{O PARADIGMA DA ECONOMIA COLABORATIVA: UM NOVO OLHAR SOBRE A PRODUÇÃO, O CONSUMO E A ORGANIZAÇÃO DO TRABALHO}

O contexto da globalização possibilita, constantemente, o surgimento de diversas mudanças na sociedade e a mais significativa delas ocorre, sem dúvida alguma, na esfera produtiva.

De acordo do Rifkin (2012), a terceira revolução industrial, ocorrida após a Segunda Guerra Mundial, ao ampliar e fomentar o uso de tecnologias avançadas no sistema de produção, ocasionou mudanças na forma de organização do trabalho. E uma dessas mudanças se deu com a necessidade de repensar novas formas de produzir bens e serviços dentro de um paradigma em que os recursos renováveis sejam utilizados de forma colaborativa (RIFKIN, 2012, p.137).

Do ponto de vista econômico e estrutural, as relações de produção do sistema capitalista industrial começam a perder terreno para um novo modelo de economia. Uma economia que propõe um rompimento radical com o padrão de consumo e com a forma de organização do trabalho em vigor há décadas nas sociedades capitalistas. Esse modelo econômico, conhecido como economia colaborativa ou economia compartilhada vem ganhando cada vez mais espaço nas sociedades atuais e seus benefícios e consequências estão começando a ser discutidos.

A economia colaborativa ou economia compartilhada surgiu em reposta à grave crise econômica de 2008 e aos anseios de uma nova e crescente geração de consumidores, que, preocupados com a preservação dos recursos naturais e do meio ambiente, optam por consumirem produtos e utilizarem serviços de empresas que demostram ter compromisso com a sustentabilidade. Romero e Garcia (2015, p. 69) definem economia colaborativa como "[...] um sistema onde se compartilha e troca produtos e 
serviços através de plataformas digitais, com a reputação e a confiança de um melhor serviço como eixo da decisão de compra-venda [...]"

Dessa forma, a economia colaborativa se sustenta nos pilares do consumo colaborativo e da produção colaborativa, e tem na tecnologia, mais precisamente nas plataformas digitais, seu instrumento de realização.

O consumo colaborativo, primeiro pilar da economia colaborativa, definido acima como sistema de compartilhamento de bens e serviços, constitui-se numa alternativa ao hiperconsumo do capitalismo industrial, e se efetiva através de ações colaborativas entre os sujeitos, como o empréstimo, a partilha e a troca de produtos ou prestações de serviços (BOTSMAN; ROGERS 2011).

Esses três fundamentos do consumo colaborativo, partilha, troca ou empréstimo nos permitem compreender que na economia colaborativa há a valorização do acesso às coisas em relação à posse das mesmas, bem como que a ideia de consumo consciente se contrapõe à ideia do consumo pelo consumo e o anseio por qualidade de vida e por uma economia sustentável que se edifica em detrimento a um modelo econômico e que coloca as coisas acima das pessoas e acredita que o meio ambiente é uma fonte de recursos inesgotáveis.

Já a produção colaborativa ou compartilhada, segundo pilar da economia colaborativa, é definida como um processo criativo de cunho coletivo realizado por meio do compartilhamento de conhecimentos entre vários sujeitos no mundo todo. Entre alguns princípios da economia colaborativa podemos citar:

1 ativos abertos acessíveis $>$ ativos fechados. Os ativos abertos proporcionam mais valor do que os ativos fechados por serem utilizados com mais eficiência e por nos permitirem descobrir continuamente novas e valiosas utilizações

2 mais mentes em rede $>$ menos mentes muradas. Um número maior de pessoas é mais inteligente que um número menor de pessoas, mas só quando elas estão conectadas em rede.

3 benefícios de abertura > problemas de abertura. Coletivamente, as oportunidades vantajosas da inovação e da aprendizagem compartilhada são muito maiores do que os problemas desvantajosos, como mau 
comportamento, que podem ser identificados com sistemas de avaliações e redes de confiança.

4 eu recebo > eu dou .Individualmente, cada pessoa que contribui com ativos a uma plataforma necessariamente recebe mais do que dá. É assim que funcionam a Winipedia, as refeições comunitárias e os impostos que pagam por bibliotecas publicas e pela defesa nacional. (Chase, 2015,p. 289).

Esses princípios evidenciam algumas mudanças no sistema produtivo do capitalismo industrial. Mudanças que se devem basicamente ao emprego da tecnologia, que facilita a interação entre diversos colaboradores motivados pela vontade de se conectar com os outros e de compartilhar seus conhecimentos e experiências, a fim de produzirem uma ferramenta tecnológica inovadora ou um produto que possa ser colocada à venda no mercado e lhes trazer benefícios econômicos.

Na compreensão de Romero e Garcia (2015),

$\mathrm{O}$ verdadeiro potencial deste modelo reside na integração de várias pessoas no processo de geração de valor, tanto econômico quanto social. Ao estabelecer que cada indivíduo pode trabalhar em uma área diferente de especialização, nesta economia, descobre-se que existe um potencial infinito de possibilidades de criação, inovação e, inclusive, empoderamento financeiro em pequenos, médios e grandes projetos

Sendo assim, na economia colaborativa temos uma valorização do empreendedorismo e do trabalho autônomo especializado voltado para a construção de projetos que prometem trazer o empoderamento econômico de seus idealizadores.

A produção colaborativa ou compartilhada está pautada na confiança e na solidariedade entre as pessoas. Uma vez que a produção de bens e a prestação de serviços na economia colaborativa são realizadas de forma compartilhada, a confiança e a solidariedade entre os parceiros e colaboradores tornam-se indispensáveis ao sucesso dos negócios, haja vista que nessa modalidade de produção, o segredo da fábrica e a necessidade de patentes são incompatíveis com a prática de produção colaborativa. 
A economia colaborativa está em ascensão em muitos países e as mudanças que ela traz à economia terá seus reflexos em outras esferas sociais e, em especial, no âmbito jurídico.

\section{A NEGAÇÃO DA RELAÇÃO DE EMPREGO E A (DES)ÇONSTRUÇÃO DO CONCEITO DE ATIVIDADE- FIM NA PERSPECTIVA DA ECONOMIA COLABORATIVA}

Na perspectiva da economia colaborativa o conceito de relação de trabalho strictu sensu (relação de emprego) alicerçado no elemento subordinação, condição sine qua non para caracterizar a relação de trabalho, praticamente não existe.

Para Delgado (2007, p. 36),

[...] o conceito de subordinação hoje dominante é o que a compreende como a situação jurídica, derivada do contrato de emprego, em decorrência da qual o trabalhador acata a direção laborativa proveniente do empregador. É uma situação jurídica que se expressa por meio de certa intensidade de ordens oriundas do poder diretivo empresarial, dirigidas ao empregado.

É justamente essa subordinação associada ao poder diretivo que o modelo de produção idealizado pela emergente economia colaborativa vem romper. A economia colaborativa tem como base de realização do processo produtivo as plataformas de participação, onde empresas sem sede física contam com colaboradores de diversos lugares do mundo que conectados a uma rede social (Skype, WhatsApp, Facebook) produzem bens materiais, criam códigos abertos e prestam serviços.

De acordo com Chase $^{9}$ (2015, p. 177), a economia compartilhada está aos poucos criando uma força de trabalho independente, porque no

\footnotetext{
${ }^{9}$ Robin chase, uma das cofundadoras da Zipcar, empresa de compartilhamento de veículos, é uma dos principais defensores da economia colaborativa. Ela idealizou um modelo de plataforma de participação a qual chama de Peers Inc, plataforma em que a capacidade excedente associada a participação de pessoas que colocam seus talentos, bens ou serviços para serem compartilhados, forma uma estrutura de economia compartilhada. Segundo Chase $(2015$, p.51) "Peers pode ser empresas, grandes e pequenas [...], fornecedores,
} 
modelo de trabalho colaborativo ou compartilhado não existe subordinação entre quem executa e quem contrata o serviço. Não existe o poder diretivo do empregador sobre os empregados. Na economia colaborativa os trabalhadores são, em suma, autônomos, empreendedores e freelanceres. Pessoas que procuram um trabalho flexível em que possam marcar seus horários, expor seus talentos de forma livre e desenvolver suas atividades laborais onde quiserem.

Para a autora,

[...] o paradigma colaborativo valoriza o agenciamento econômico. A resiliência, a paixão, a aprendizagem, a autonomia e contribuições sem igual. De maneira similar, a economia colaborativa minimiza a necessidade de se 'prostituir' a algum empregador, compensa a falta de benefícios e reduz a importância de proteções por parte da empresa [...]. (CHASE, 2015, p. 62)

Isso nos revela que, no modelo produtivo e de prestação de serviço da economia colaborativa, existe a negação da relação de trabalho strictu sensu (relação de emprego), justamente porque esse tipo de economia reduz a necessidade de alguém vender sua força de trabalho para outrem. E como não existe vínculo empregatício, a economia colaborativa tende, por um lado, a beneficiar empresas, reduzindo os encargos, principalmente com folha de pessoal e, por outro prejudica os trabalhadores, uma vez que, inexistindo relação de emprego, tampouco existem direitos trabalhistas.

Essa mudança de paradigma da produção acarreta o fim da hierarquia produtiva do modelo fordista e aos poucos transforma e amplia o modelo horizontal de gerenciamento toyotista, porque, na produção compartilhada, os consumidores também podem fazer parte do processo de produção de bens e criação de códigos abertos. Tapsccot e Willians (2006, p.60) afirmam que,

[...] empresas hierárquicas estão adotando modelos colaborativos, auto-organizativos de redes de

dispositivos conectados possibilitando a utilização do Skype ou pessoas que postam suas fotos no Fecebook ou publicam vídeos no yutube." Já a Inc funciona como uma "agencia" que possibilitada a colaboração entre os peers. 
negócios (business-webs ou b-webs) nas quais massas de consumidores, funcionários, fornecedores, parceiros e até mesmo concorrentes criam valor conjuntamente sem que haja um controle gerencial direto.

Conforme colocam esses autores, os modelos colaborativos de produção vêm sendo adotados por empresas que antes se respaldavam em modelos produtivos hierárquicos. E isso se deve à necessidade das empresas se manterem fortes e competitivas no mercado. Ignorar a revolução tecnológica e o perfil participativo do próprio consumidor pode muitas vezes levar empresas à falência.

Conforme Tapsccot e Willians (2006, p.76),

Hoje, bilhões de pessoas conectadas em todo o planeta podem cooperar para fazer quase tudo o que requer criatividade humana, um computador e uma conexão à internet. Ao contrário de antes, quando os custos de produção eram altos, as pessoas podem colaborar e compartilhar as suas criações a um custo muito pequeno. Isso significa que os indivíduos não dependem mais dos mercados ou de empresas com uso intensivo de capital para produzir ou comercializar todos os bens e serviços que desejam. Na verdade, uma proporção cada vez maior de coisas que valorizamos (inclusive jornais) pode agora ser produzida por nós mesmos, sozinhos ou em cooperação com as pessoas com as quais interagimos socialmente - simplesmente porque assim desejamos.

Isso denota que nos modelos colaborativos de produção, a cooperação entre as pessoas através da internet torna o custo da produção mais barato uma vez que, necessariamente, não é mais preciso a existência de empresas ou de mercados para produzir e comercializar produtos e serviços.

Paralelo a isso, na produção colaborativa ou compartilhada, é a pessoa que presta o serviço ou que produz o bem e quem determina quais tarefas quer realizar de acordo com suas habilidades e talentos. Tapsccot e Willians defendem essa ideia ao afirmarem que:

[...] Ao voluntariamente se auto-selecionarem para tarefas criativas e com uso intensivo de conhecimento, 
as pessoas têm mais chance do que os gerentes de escolher tarefas para as quais estão distintamente capacitadas. Afinal de contas, quem provavelmente conhece melhor a gama de tarefas para as quais você está mais bem preparado - você ou o seu gerente? (TAPSCCOT; WILLIANS, 2006. p. 77)

Nesse sentido, vemos que o paradigma da economia colaborativa com seu modelo de produção compartilhado vem, aos poucos, rompendo com os modelos clássicos de produção que ainda persistem nas sociedades capitalistas do século XXI, seja por negar os elementos inerentes à configuração da relação de emprego (subordinação e poder diretivo), ou por propor um modo de produção que rompe com as formas tradicionais de organização do trabalho fordista e toyotista.

$\mathrm{O}$ fato é que, estamos diante de uma proposta de mudança radical na esfera econômica, que parece revolucionar o mundo do trabalho. Algo que nem mesmo a revolução tecnológica e os modelos de produção fordista e toyotista foram capazes de fazer: alterar o modelo da relação de trabalho subordinado (PORTO, 2008, p. 215).

A forma de produzir na economia colaborativa altera esse modelo de relação de trabalho, porque suprime o elemento subordinação dessa relação. Dessa forma, podemos dizer que na perspectiva da economia colaborativa há uma desconstrução do conceito de relação de trabalho subordinado (relação de emprego) e até mesmo do conceito de atividade-fim, enquanto atividade caracterizada pela relação de subordinação entre empregado e empregador. No tocante à atividade-fim, vemos que a ausência de vínculo subordinativo pode até mesmo impedir a identificação dos responsáveis pelos riscos dessa atividade, ou seja, não é possível identificar o responsável pelo possível risco que a atividade possa trazer à sociedade ou aquele que responde pelos encargos trabalhistas.

\section{A (IN)EXISTÊNCIA DA TERCEIRIZAÇÃO NO PARADIGMA DA ECONOMIA COLABORATIVA}

Se tomarmos como base o conceito de terceirização do professor Márcio Túlio Viana, para quem essa palavra indica a inserção de um terceiro na cadeia produtiva, podemos aferir que na economia colaborativa existe uma espécie de inserção de um terceiro na relação produção e de 
serviços, mas não existe uma terceirização enquanto fenômeno que envolve uma relação trilateral (empresa tomadora, empresa prestadora e obreiro). Na economia colaborativa, a relação que se estabelece entre o terceiro que presta o serviço e a plataforma que gerencia essa prestação diferese do modelo de terceirização toyotista, haja vista, que nesse último, uma parte da produção ou passa ser feita fora da empresa ou contrata-se alguém de fora para realizá-la. No modelo toyotista de terceirização, descentralizase a produção, mas ainda existe o poder direto, ainda há traços de subordinação e contrato de trabalho, o que gera vínculo entre as partes.

Em contraponto, na economia colaborativa, a prestação de serviço é autônoma. Não há sentido para existência de contrato de trabalho nem para relação de trabalho subordinado, o que não gera vínculo nem obrigações entre as partes.

$\mathrm{Na}$ economia colaborativa, o interesse pela inserção de um terceiro no ciclo produtivo se deve à necessidade do uso de talentos e habilidades que por vezes estão separados por fronteiras físicas e que graças à tecnologia, mais precisamente a internet, unem-se com o objetivo de produzir bens e prestar serviços.

De acordo com Chase, fora da empresa há mais pessoas talentosas que dentro dela. E para comprovar sua tese, a autora cita o processo de construção do smartphone, que é fruto da inclusão de aplicativos desenvolvidos por diversas pessoas e profissionais, desde um simples amador até engenheiros (CHASE, 2015, p. 63-64).

O terceiro envolvido na esfera produtiva não é denominado trabalhador e sim colaborador, empreendedor, parceiro ou até mesmo um voluntário. Exemplos disso são os intelectuais de diversos países do mundo que, ao compartilharem seus conhecimentos na rede, criaram a Winkpedia, ou que, ao desenvolverem os códigos abertos, deram origem ao Linux. $\mathrm{O}$ terceiro pode ser uma simples pessoa que, ao viajar, decide ofertar vagas de seu carro para quem segue para o mesmo destino, como o que acontece no serviço de carona paga ofertado no BlaBlaCar; ou alguém que para ganhar um dinheiro extra nas horas livres, presta serviços como entregador para Amazon Flex; também pode ser um aplicativo como o Uber que disponibiliza aos seus usuários serviço de automóveis com condutor, uma espécie de táxi de luxo.

A fim de ilustração, recentemente em duas capitais brasileiras (São Paulo e Rio de Janeiro), o uso do aplicativo Uber gerou uma séria polêmica ao provocar brigas entre os taxistas e prestadores de serviços que 
utilizam esse aplicativo. Os taxistas reclamavam da concorrência desleal e ilegalidade do serviço, uma vez que os prestadores de serviço da Uber não pagam impostos. A Uber, por sua vez, por meio de seu representante, disse que não pode ser regulamentada, porque é um aplicativo e não uma empresa.

Vale salientar que o serviço de transporte oferecido pela Uber assim como o serviço de táxi, não configura um serviço público. Trata-se de serviços de transporte privado, mas de utilidade pública, submetendose, portanto à livre concorrência e iniciativa privada, mas que por prestarem serviços que atendem aos interesses da sociedade carecem de regulamentação estatal. No entanto, a discussão entre taxistas e motoristas da Uber perpassa justamente pela questão da regulamentação dessa plataforma tecnológica, haja vista que alguns taxistas são contrários a essa regulamentação. Recentemente em reunião com os lideres sindicais dos taxistas de São Paulo, o prefeito dessa capital, Fernando Haddad, arguiu que se os serviços da Uber não forem regulamentados os taxistas "vão desaparecer pela concorrência predatória" (SOUZA, 2016).

Conforme Chase (2015, p. 177), com a economia compartilhada "[...] Teremos uma multidão de taxistas autônomos, uma profusão de lugares para nos hospedar, um exército de entregadores... e os salários vão cair [...]". Esse pensamento releva uma das faces da terceirização do capitalismo industrial que a economia colaborativa pretende fomentar: a precarização do trabalho e, consequentemente, a redução de encargos da empresa.

Traçando um paralelo entre o modelo de terceirização toyotista e o modelo de relação de trabalho proposto pela economia colaborativa, veremos que, no primeiro, busca-se fora da empresa uma mão-de-obra barata e especializada ou delega-se uma etapa do ciclo produtivo. A organização do trabalho é feita de modo a permitir a participação do trabalhador em diversas etapas do processo produtivo, o poder diretivo é flexível e o trabalho é remunerado. O segundo também busca mão-de-obra especializada e se volta, exclusivamente, para explorar os talentos que cada pessoa tem de melhor, mas nele não existe o poder diretivo e o trabalho pode não ser remunerado.

Sendo assim, vemos que a relação de trabalho na economia colaborativa embora não caracterize um modelo de terceirização nos moldes da relação trilateral, tem as mesmas consequências da terceirização toyotista. Ela, de certa forma, principalmente no que diz respeito aos efeitos, implica uma nova roupagem dessa terceirização, porém mais perigosa, porque, ao 
contrário dos modelos produtivos anteriores, o modelo de relação de trabalho da economia colaborativa elimina a relação de emprego.

\section{AS IMPLICAÇÕES DA NEGAÇÃO DA RELAÇÃO DE EMPREGO E DA (DES)CONSTRUÇÃO DO CONCEITO DE ATIVIDADE-FIM NA ECONOMIA COLABORATIVA PARA O DIREITO DO TRABALHO}

O Direito do Trabalho tem sua razão de existência alicerçada na figura da relação de trabalho subordinado, ou seja, relação de emprego. O arcabouço de normas que constitui esse ramo do Direito regula as relações entre empregador e empregado e visa principalmente à proteção do obreiro, parte hipossuficiente dessa relação. Onde não há relação de trabalho subordinado não há incidência das normas trabalhistas, pois a subordinação se configura no cerne da relação empregatícia.

Esse pensamento é corroborado por Porto (2008) ao afirmar que,

[...] é exatamente a presença dessa relação que atrai a incidência das normas de Direito do Trabalho, que asseguram vantagens e garantias ao prestador de serviço. Em outras palavraras: se não há subordinação, não há relação de emprego, não gozando o trabalhador dos direitos assegurados pela ordem jurídica [...] (PORTO, 2008, p. 213)

Nesse sentido, a subordinação é componente fundamental para caracterizar a relação de emprego e legitimar a sanção das normas trabalhistas. No entanto, algumas dessas normas vêm sendo burladas, no decorrer dos tempos, por mecanismos e institutos que restringem os direitos dos obreiros. Atualmente, um dos institutos utilizados para burlar a legislação trabalhista é a terceirização.

Contudo, paralelo a isso, começa a despontar no cenário econômico mundial ${ }^{10}$, o modelo de produção e de relação de trabalho proposto

\footnotetext{
${ }^{10}$ A economia colaborativa é mais perceptível nos Estados Unidos da América e em muitos países do continente europeu. Nos países em desenvolvimento como é o caso do Brasil, sua atuação tem sido um pouco mais contida, mas é possível visualizarmos os pilares da economia colaborativa na iniciativa do Banco Itaú em incentivar o compartilhamento de bicicletas (consumo colaborativo) e no uso do aplicativo Uber (prestação de serviço por
} 
pela economia colaborativa que, como vimos no tópico anterior, tem efeitos semelhantes ao da terceirização.

A relação de trabalho da economia colaborativa, como vimos no tópico anterior, valoriza, essencialmente, o trabalho autônomo não diretivo e realizado de forma colaborativa. Contudo, o objetivo é o mesmo da terceirização em moldes toyotista: reduzir os custos da produção e restringir direitos trabalhistas.

Chase (2015), ao defender a plataforma de participação desenvolvida por ela, a Peers In, revela também alguns dos aspectos negativos que a economia colaborativa acarreta para os trabalhadores. Segundo a autora, "[...] na economia da Peers Inc há um grande potencial de driblar as leis trabalhistas de salário justo. [....] (CHASE, 2015, p.176). E, uma vez que esse modelo de produção não gera dependência econômica, não existe o hipossuficiente, o que impede a aplicação de normas trabalhistas.

Tal assertiva evidencia que nesse modelo produtivo não há estipulação mínima de um padrão salarial nem mesmo para profissionais de mesma categoria. Aliás, na economia colaborativa, o que existe é um forte incentivo ao trabalho autônomo, o que nos leva a crer que nesse modelo econômico as categorias profissionais tendem a desaparecerem.

O surgimento de um grande contingente de trabalhadores autônomos põe em risco uma gama de conquistas da classe trabalhadora não só no que diz respeito à seara trabalhista como também previdenciária (CHASE, 2015, p.180). Além disso, fere o princípio basilar do Direito do Trabalho, o Princípio da Proteção, colocando em risco a própria existência do Direito do Trabalho, pois sua razão de existir é salvaguardar os direitos do obreiro.

Segundo Delgado (2007, p. 78):

[...] O Direito do Trabalho corresponde à dimensão social mais significativa dos Direitos Humanos, porquanto tem a eficácia de regular a principal modalidade de inserção dos indivíduos no sistema socioeconômico capitalista, cumprindo o papel de lhes assegurar um patamar civilizado de direitos e garantias

compartilhamento) nas cidades do Rio de Janeiro e de São Paulo. Mais experiências sobre a economia colaborativa podem ser encontradas no sito cidade colaborativa (http://www.cidadecolaborativa.org) 
jurídicas, que, regra geral, por sua própria força e/ou habilidade isoladas, não alcançariam.

São essas normas de proteção à dignidade humana do trabalhador que o modelo de relação de trabalho da economia colaborativa fere ao sinalizar para um possível desaparecimento do emprego.

Já no que se refere à atividade-fim, podemos aferir que na proposta de relação de trabalho da economia colaborativa, a atividade-fim pode continuar sendo entendida como a atividade central da empresa, mas não é uma atividade em que exista subordinação entre prestador de serviço e contratante. $\mathrm{O}$ que parece mudar é a dinâmica de realização dessa atividade, haja vista que no modelo de produção compartilhada, realizado de forma cooperativa, não é possível identificar quem realmente responde pelos riscos dessa atividade já que todos os envolvidos no processo são colaboradores.

Nesse sentido é importante ressaltar que, embora a economia colaborativa e seus modos de produção e de relação de trabalho ainda sejam algo muito recente nas sociedades contemporâneas, o Direito do Trabalho, assim como outros ramos do Direito, deve se atentar para as mudanças que esse modelo de economia acarreta para a sociedade. Mudanças que certamente fomentarão sérios conflitos a serem resolvidos pelo legislador e pelo Poder Judiciário.

Frise-se que, se tomarmos como referência o caráter teleológico do Direito do Trabalho, veremos que sua função social é promover melhorias nas condições do pacto laboral (DELGADO, 2015, p. 46).

Embora a relação empregatícia seja a principal atividade laboral regulamentada pelas normas trabalhistas e o fenômeno mais importante sob o qual se estruturou o próprio Direito do Trabalho, não devemos esquecer que existem outras relações de trabalho, que mesmo desprendidas da subordinação, são protegidas por esse ramo do Direito, a exemplo dos trabalhadores avulsos.

No tocante ao estudo em tela, podemos aferir que, a relação de trabalho da economia colaborativa traz resultados nefastos ao conceito de relação de emprego e de atividade-fim, e pode macular o caráter teleológico do Direito do Trabalho, pois parece fulminar o sentido dos princípios justrabalhistas da Proteção e da Continuidade da Relação de Emprego, bem como o Princípio da Valorização do Trabalho consagrado na carta Magna. Isso porque nessa proposta de relação de trabalho, como já frisamos, não 
há perspectiva de relação empregatícia e não há valorização do trabalho, o que sinaliza para uma possível violação da principal função do Direito do Trabalho: impedir a exploração do trabalho como elemento de acumulação riquezas para uma determinada classe.

O Direito do trabalho exerce importante função política na coordenação das condições normativas que disciplinam a mais importante relação entre o homem e o capital, o trabalho, aqui entendido numa perspectiva ampla como uma atividade desenvolvida para aferir renda para o obreiro e lucro para o patrão. Essa função política também se encontra ameaçada no contexto da economia colaborativa. E colocar em rico essa função pode significar o fim do ideal de uma sociedade justa, livre e solidaria.

\section{CONSIDERAÇÕES FINAIS}

O presente estudo mostra que a emergência da economia colaborativa traz uma proposta de mudança radical na esfera econômica que parece revolucionar o mundo do trabalho. Essa proposta tem seu cerne em um modelo de trabalho que (des)constrói o conceito de relação de trabalho strictu sensu (relação de emprego) ao negar a existência da relação de trabalho subordinado, bem como impede a identificação dos responsáveis pelos riscos da atividade-fim.

Nota-se que, ao contrário do que acontece no modelo de relação de trabalho toyotista, a economia colaborativa sugere, praticamente, o fim da relação de emprego, ao levantar a bandeira do trabalho autônomo, empreendedor e até mesmo voluntário. Assim, o modelo colaborativo de produção traz um novo formato de terceirização, mas sua finalidade continua a mesma: burlar as leis trabalhistas.

O Direito do trabalho, enquanto instrumento de garantias dos direitos e da dignidade do obreiro, fundamenta-se no Princípio da Proteção. Esse princípio condiciona a elaboração das normas trabalhistas ao impor que elas sejam criadas para beneficiar o trabalhador e melhorar sua condição econômica e, consequentemente, social.

Dessa forma, o contexto atual coloca para o legislador a tarefa de pensar soluções para os possíveis conflitos que a economia colaborativa, certamente, ocasionará a sociedade, principalmente na esfera trabalhista. 


\section{REFERÊNCIAS}

ALVES, Giovanni. O espírito do toyotismo - reestruturação produtiva e "captura" da subjetividade do trabalho. In: Confluências- Revista Interdisciplinar de Sociologia e Direito. vol.10, n. 1, 2008, p. 99-121

ANTUNES, Ricardo. Adeus ao Trabalho? Ensaio sobre as metamorfoses e a centralidade do trabalho. 15. ed. São Paulo: Cortez, 2011

BASSO, Guilherme Mastrichi. Terceirização e mundo globalizado: o encadeamento produtivo e a complementaridade de serviços como potencializadores da formalização de contratos. In: Revista TST, Brasília, vol. 74, n. 4, out/dez 2008, p. 89-116

BATISTA, Erika. Formas de Organização do trabalho: Apontamentos para uma "Anti-Sociologia do Trabalho. In: Aurora, ano II, n. 2. Junho, 2008

BOTSMAN, Rachel. ROGERS, Roo. O que é meu é seu: como o consumo colaborativo vai mudar o nosso mundo. Tradução: Rodrigo Sardenberg. Porto Alegre: Bookman, 2011.

CHASE, Robin. Economia compartilhada: como pessoas e plataformas da Peers Inc. estão reinventando o capitalismo. Tradução: Cristina Yamagami. São Paulo: HSM do Brasil, 2015

CHESNAIS, François. As origens comuns da crise econômica e da crise ecológica. In: O Olho da História, n. 13, Salvador (BA), dezembro de 2009

COUTINHO, Grijalbo Fernandes. Terceirização: máquina de moer gente trabalhadora. São Paulo: LTr, 2015

DELGADO, Maurício G. Curso de Direito do trabalho. 14. ed. São Paulo: LTr, 2015.

. Direitos Fundamentais na relação de trabalho. In: Revista de Direitos e Garantias Fundamentais, $n^{\circ}$ 2, 2007

GIOSA, Lívio A. Terceirização uma abordagem estratégica. 3. ed. são Paulo: pioneira, 1994

HOBSBAWM, Eric. Era dos Extremos: o breve século XX: 1914-1991.Tradução: Marcos Santarrita. São Paulo: Companhia das Letras, 1995

JÚNIOR. José Cairo. Curso de Direito do Trabalho: Direito Individual e Coletivo do Trabalho. 8. ed. Salvador, Bahia: JusPodivm, 2014

JÚNIOR, Ophir. Cavalcante. A terceirização das Relações Laborais. São Paulo: LTr, 1996.

MAIOR, Jorge Luiz Souto. Curso de Direito do trabalho: teoria geral do direito do trabalho. v.1 - parte 1, São Paulo, LTr, 2011.

MARTINS, Sergio Pinto. A terceirização e o Direito do Trabalho. 13. ed. São Paulo: Atlas S.A, 2014

MENEZES, Marcos. MENDES, Barberino. Terceirização: o que é e o que pode ser. São Paulo: Estúdio Editores.com, 2014

PORTO, Lorena Vasconcelos. Por uma releitura do conceito de subordinação jurídica. In: : VIANA, Márcio Túlio. TERRA, Luciana Soares Vidal. Délcio de 
Abrel e Silva Jr. (coord.). Direito do Trabalho e Trabalhos sem Direitos. Belo Horizonte: Mandamentos, 2008, capit. 24, p. 209-224

SOBRINHO, Zéu Palmeira. Terceirização e restruturação produtiva. São Paulo: LTr, 2008.

SOUZA, Felipe. Haddad diz que taxistas desaparecerão se Uber não for regulamentado em SP. In: Folha de São Paulo on line. Disponível in: $<$ http://www.folha.uol.com.br/cotidiano/2016/01/1734472-haddad-diz-quetaxistas-desapaecerao-se-uber-não-for-regulametado-em-sp.shtml. Acesso em, 28 de janeiro de 2016

RIFKIN, Jeremy. A Terceira Revolução Industrial: como o poder lateral está transformando a energia, a economia e o mundo. Tradução: Maria Lúcia Rosa. São Paulo: M. Books do Brasil, 2012

ROMERO, Alejandro. GARCÍA, Luisa. Economia Colaborativa: A Revolução do Consumo Mundial. Disponível in: <http://www.revista-uno.com.br/economia-colaborativa-a-revolucao-do-consumo-mundial//. Acesso em 02 de novembro de 2015

SARAIVA, Renato (org). CLT: Consolidação das Leis do trabalho. 6. ed. São Paulo: Métodos, 2012.

TAYLOR, Frederick Wilson. Princípios de administração científica. Tradução: Arlindo Vieira Ramos. 8. ed. São Paulo: Atlas, 1990

TORRES, Washington. As relações de trabalho lato sensu e os novos princípios positivados no código civil. In: VIANA, Márcio Túlio. TERRA, Luciana Soares Vidal. Délcio de Abrel e Silva Jr. (coord.). Direito do Trabalho e Trabalhos sem Direitos. Belo Horizonte: Mandamentos, 2008, capit. 31, p. 265-273 VIANA. Márcio Túlio. Para entender a terceirização. São Paulo: LTr, 2015 